\title{
Study on Translations of Five Xing Theory of TCM and Its Core Terminologies
}

\author{
Jiaxing $\mathrm{Ou}$ \\ University of Shanghai for Science and Technology, Shanghai, China \\ Yan Hua \\ University of Shanghai for Science and Technology, Shanghai, China
}

\begin{abstract}
Against the backdrop of the Belt and Road Initiative, the going-out policy of Chinese culture is ensured by a strong language tool. Now the going-out of Traditional Chinese Medicine (TCM) is leading an irreversible trend for TCM is widely expanded as the significant part of traditional Chinese culture. Then, the precise translation of TCM is expected to be a guarantee for its internationalization. To date, mistranslation, omission and inaccuracy have extremely interfered with the cultural exchanges with other countries, affecting the quality of translations. From the aspect of the translations of Five Xing Theory of TCM and its core terminologies, the paper purports to compare WHO International Standard Terminologies on Traditional Medicine in the Western Pacific Region (IST) and International Standard Chinese-English Basic Nomenclature of Chinese Medicine (ISN). And then it can be concluded that when translating Five Xing Theory of TCM and its core terminologies, literal translation and transliteration should be mainly adopted and annotation is supposed to be added in proper situation so as to achieve accurate translation and better the promotion of transmission of TCM.
\end{abstract}

Index Terms - translation of TCM, Five Xing Theory, The Belt and Road Initiative

\section{INTRODUCTION}

Five Xing Theory is stemmed from ancient Chinese philosophy and develops into the philosophical foundation of TCM with its basic theory combined with TCM to diagnose and prevent diseases (Sun \& Zheng, 2012). The key to TCM's international communication lies in the exact translation of basic theories of TCM. Therefore, as the important part of basic theories of TCM, standardized and normalized translation of Five Xing Theory and its core terminologies are required.

Researches on TCM translation are growingly incremental with the topics of them mostly centering on translation of terminologies and Classics, for example, The Inner Canon of Huangdi and Cold Diseases. Some studies on the translation of Five Xing Theory of TCM and its core terminologies of course can be found including related three pieces of thesis and dissertations as well as twelve journal articles. Among them, Chen (2002) highlights the significant relation between Five Xing Theory's origin and Chinese philosophy. Li (2009) analyzes the specific connotations and translation strategies of Five Xing Theory, arguing that "five movements" or "five interactions" is the viable translation. Yan (2016) mentions that translators must not translate Five Xing into Five Organs, and the imagery thinking should be reserved. In addition, annotations can also be added into translations. They all debate on the situation that whether it is proper to render "Wu Xing" into "Five elements" and they finally take different views. Though a small part of the translation of "Xiang Sheng Xiang Ke" and "Xiang Cheng Xiang Wu" are discussed in those studies, more profound exploration is still required to be achieved in order to get meaningful results. Therefore, based on the proceeding studies at home and rare literature procured outside China, the paper will give a further discussion on the translation of "Wu Xing", "Xiang Sheng Xiang Ke" and its related terminologies like "Xiang Cheng Xiang Wu", "Mu Zi", "Xiang Sheng”, "Zhi Hua" and "Sheng Fu".

\section{Five Xing (WoOd, Fire, EARTh, Metal AND Water)}

Five Xing Theory counts wood, fire, earth, metal and water as five rudimentary substances that constitute everything in the universe, making them an organic whole. The ancients combine Five Xing with Five Organs' physio-pathology so as to elucidate Five Organs' operation and diagnose diseases in human body. All in all, Five Xing can not be perceived one by one and it is suggested that we dawn on Five Xing in an associative and unitive way given that the extensive connotations are contained in them.

Chinese character "Wu Xing" was first mentioned in Shang Shu. Shang Shu, in stating what "Wu Xing" is, says, "Wu Xing refers to water, fire, wood, metal, and earth" (Mu, 2009, P. 128). And it still explains the features of those Xing: wood stands for growing; fire represents heat and rising; earth symbolizes loading; metal features settlement and constriction; and water means moisture and descending. 
Five elements have their unique functions and they promote and restrain each other. Such an interplay process, keeping them active in the movements of "Xiang Sheng Xiang Ke", is far more than isolated or motionless.

IST and ISN translate Five Xing into five phases and five elements/five phases respectively. In reference to Mu, Huo, Tu, Jin and Shui (Chinese characters), both IST and ISN translate them like this: Wood, Fire, Earth, Metal and Water. The author holds that five phases and five elements would be too simple to perceive Five Xing, unable to convey its meanings in a systematic way. Without a concert English equivalent word for "Xing" which contains quite a few implications, "phases" and "elements" fail to express its exact meaning. TCM's Five Xing highlights the interactional movements among Five Xing rather than the simple five elements nor each isolated phase. Furthermore, the relationship between the systematically interactional nature in Five Organs and Five Xing's features truly proves Five Xing's inner dynamic connections. And in Plain Conversation of The Inner Canon of Huangdi, the relation among Five Xing, Five Organs and Five Flavours (sweet, sour, bitter, pungent and salty) is fully stated. Therefore, the author considers that it is the most appropriate to render "Wu Xing" into Five Xing like Yin Yang and Qi. And the translations of Wood, Fire, Earth, Metal and Water that offered by IST and ISN are feasible because neither "Tu" is literally translated into "Soil" nor "Jin" is rendered into "Gold". Compared with "Soil" and "Gold" which are too restrictive to present the true meanings of "Tu" and "Jin", "Earth" and "Metal" cover more extensive information. So, the above discussed translations of each Xing are most suitable.

TABLE 1

THE TRANSLATIONS OF "WU XING XUE SHUO" AND “WU XING” BY IST AND ISN

\begin{tabular}{|l|l|l|}
\hline & 五行学说 & 五行 \\
\hline IST & Five Phase Theory & five phases \\
\hline ISN & Five Phase Theory & five elements; five phases \\
\hline
\end{tabular}

TABLE 2

THE TRANSLATIONS OF "MU", "HUO", "TU", “JIN", AND "SHUI” BY IST AND ISN

\begin{tabular}{|l|l|l|l|l|l|}
\hline & 木 & 火 & 土 & 金 & 水 \\
\hline IST & wood & fire & earth & metal & water \\
\hline ISN & wood & fire & earth & metal & water \\
\hline
\end{tabular}

\section{Generation And Restriction among Five Xing (Mother And Child, Xing Being Restricted And UN-RESTRICTED)}

"Generation and Restriction among Five Xing", performing in a dynamic, ordered and balanced manner, refers that Five Xing promotes and restrains each other, from which the concept of "Mother and Child" as well as "Xing Being Restricted and Unrestricted" are extended.

"Xiang Sheng" is the generation and promotion among Five Xing in order. The rule of "Xiang Sheng" among Five Xing is as follows: Mu Sheng Huo; Huo Sheng Tu; Tu Sheng Jin; Jin sheng Shui; Shui Sheng Mu.

"Xiang Ke" refers to the restriction and restraint among Five Xing in order. The rule of "Xiang Ke" among Five Xing falls like this: Mu Ke Tu; Tu Ke Shui; Shui Ke Huo; Huo Ke Jin; and Jin Ke Mu.

IST translates "Sheng" into "engendering or generating" and renders "Mu Sheng Huo" into "Wood engenders Fire". And "Ke" is translated into "restrain" while "Mu Ke Tu" is rendered into "Wood restrains Earth".

In ISN, "generation of five elements/phases" is the English correspondence of "Wu Xing Xiang Sheng" and "restriction among five elements/phases" is the translation of "Wu Xing Xiang Ke". And for the translation of "Mu Sheng Huo" and "Mu Ke Tu", "Wood generating Fire" and "Wood Restrains Earth" are given.

From the above listed translations, the core words used in the translation of "Xiang Sheng Xiang Ke" are "engender", "generate", "restrain" and "restrict". Looking up Longman Dictionary of Contemporary English (the $5^{\text {th }}$ edition), the author finds out the definitions of the above four words. Here is the explanation of "engender": "to be the cause of a situation or feeling" (Cai, 2014, P. 805). There are two items of the definition of "generate" - "to produce or cause something; to produce heat, electricity, or another form of energy" (Cai, 2014, P. 1044). Though "engender" and "generate" can basically express the meaning of "Xiang Sheng", its connotation of "promotion" is not covered in them. "Sheng" in Five Xing theory also means promotion, setting great store by the interplay among Five Xing. In addition, Five Xing exists in the universe naturally. In other words, people do not say one Xing produces the other Xing because of their existence of nature. Therefore, to completely and precisely translate "Xiang Sheng", more discussion should be conducted in the future.

Longman Dictionary of Contemporary English (the $5^{\text {th }}$ edition), in explaining what "restrain" means, says, "to stop someone from doing something often by using physical force; to control your own emotions or behaviour; and to control or limit something that is increasing too much" (Cai, 2014, P. 2149). With respect to the explanation of "restrict", it says, "to limit or control the size, amount, or range of something; to limit someone's actions or movements" (Cai, 2014, P. 2150). Analyzing the above meanings of "restrain" and "restrict" given by the dictionary, the author learns that both the words of "restrain" and "restrict" mean "limit" or "control". So, either "restrain" or "restrict" convey "Ke" appropriately. 
In light of "generation among Five Xing", one Xing who engenders the other Xing is called the "mother" while one Xing who is engendered by the other Xing is named "child". So, in the process of "generation among Five Xing", every Xing can be the "mother" or "child".

In terms of "Mother and Child" of Five Xing, IST translates "Mu Qi", "Zi Qi", and "Mu Zi Xiang Ji" into "mother qi", "child qi", and "mother and child affecting each other". While ISN renders "Mu Qi" and "Zi Qi" into "mother-element qi/mother-phase qi" and "child-element qi/child-element qi/edema of legs in pregnancy". Adding annotations and stating the origins of "mother" and "child" with parenthesis, the author think, are feasible strategies when translating "mother qi", "child qi" and "mother and child affecting each other".

For examples:

mother qi (Wood engenders Fire, so Wood is mother and then Fire is child. So are other Xing.)

child qi (Wood engenders Fire, so Wood is mother and then Fire is child. So are other Xing.)

In reference to "restriction among Five Xing", one Xing restrains the other Xing. Then we say that the other Xing is restrained by one Xing, and one Xing is un-restrained by the other Xing. So, every Xing can be restricted and un-restricted by other Xing. This is where Chinese "Suo Sheng" and "Suo Busheng" come from. Chinese character "Sheng" means "to win". "Suo Sheng" means "being won" while "Suo Busheng" implies "being un-won". In this situation, we could say that "being won" is "being restricted" and "being un-won" is "being un-restricted". For example, "Wood restrains Earth" can be seen as "Wood wins Earth", so "Tu Wei Mu Suo Sheng" should be translated into "Earth being restricted by Wood". And "Mu Wei Tu Suo Busheng" are supposed to be rendered into "Wood being un-restricted by Earth".

The translations of Chinese "Suo Sheng", "Suo Busheng", "Mu/Huo/Tu/Jin/Shui Wei Jin/Shui/Mu/Huo/Tu Suo Sheng" and "Mu/Huo/Tu/Jin/Shui Wei Tu/Jin/Shui/Mu/Huo Suo Busheng" are not mentioned in IST. Nevertheless, ISN translates them into "element being restricted", "elements being un-restricted", "Wood/Fire/Earth/Metal/Water being restricted by Metal/Water/Wood/Fire/Earth" and "Wood/Fire/Earth/Metal/Water being un-restricted by Earth/Metal Water/Wood/Fire". All those translations conform to the original based on "restriction among Five Xing".

TABLE 3

\begin{tabular}{|l|c|c|c|c|}
\hline \multicolumn{2}{l}{ THE TRANSLATIONS OF “XIANG SHENG”, “XIANG KE”, “WU XING XIANG SHENG”, AND “Wu XING XIANG KE” BY IST AND ISN } \\
\hline IST & engendering/generating & 相克 & 五行相生 & 五行相克 \\
\hline ISN & $/$ & restrain & $/$ & $/$ \\
\hline
\end{tabular}

TABLE 4

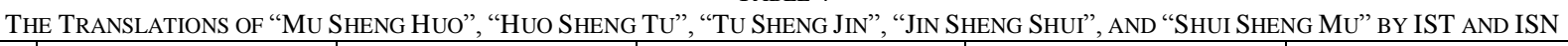

\begin{tabular}{|l|c|c|c|c|c|}
\hline & 木生火 & 火生土 & 土生金 & 金生水 \\
\hline IST & wood engenders fire & fire engenders earth & earth engenders metal & metal engenders water & water engenders wood \\
\hline ISN & wood generating fire & fire generating earth & earth generating metal & metal generating water & water generating wood \\
\hline
\end{tabular}

TABLE 5

The Translations of “Mu Ke Tu”, "HuO Ke JiN”, “Tu Ke Shui”, “Jin Ke Mu”, AND “Mu Ke HuO” BY IST AND ISN

\begin{tabular}{|l|l|l|l|l|l|}
\hline & \multicolumn{1}{|c|}{ 木克土 } & \multicolumn{1}{c|}{ 火克金 } & \multicolumn{1}{c|}{ 土克水 } & \multicolumn{1}{c|}{ 克木 } \\
\hline IST & wood restrains earth & fire restrains metal & earth restrains water & metal restrains wood & wood restrains fire \\
\hline ISN & wood restricting earth & fire restricting metal & earth restricting water & metal restricting wood & wood restricting fire \\
\hline
\end{tabular}

TABLE 6

The Translations of “Suo Sheng”, “Mu Wei Jin Zhi Suo Sheng”, “Huo Wei Shui Zhi Suo Sheng”, “Tu Wei Mu Zhi SuO Sheng”, “Jin Wei HUO ZHI SUO SHENG”, AND “SHUi WEI TU ZHI SUO SHENG” BY IST AND ISN

\begin{tabular}{|l|c|c|c|c|c|c|}
\hline & \multicolumn{1}{|c|}{ 所胜 } & 木为金之所胜 & 火为水之所胜 & 土为木之所胜 & 金为火之所胜 & 水为土之所胜 \\
\hline IST & $/$ & $/$ & $/$ & $/$ & $/$ \\
\hline ISN & $\begin{array}{c}\text { element being } \\
\text { restricted }\end{array}$ & $\begin{array}{c}\text { wood being } \\
\text { restricted by metal }\end{array}$ & $\begin{array}{c}\text { fire being restricted } \\
\text { by water }\end{array}$ & $\begin{array}{c}\text { earth being } \\
\text { restricted by wood }\end{array}$ & $\begin{array}{c}\text { metal being restricted } \\
\text { by fire }\end{array}$ & $\begin{array}{c}\text { water being } \\
\text { restricted by earth }\end{array}$ \\
\hline
\end{tabular}

TABLE 7

The Translations of “Suo Bu Sheng”, “Mu Wei Tu Zhi Suo Bu SHEnG”, “Huo Wei Jin Zhi Suo Bu ShenG”, “Tu Wei Shui Zhi Suo Bu SHENG”, “Jin Wei Mu Zhi SuO Bu ShenG”, AND “SHui Wei Huo ZHi SuO Bu SHENG” By IST AND ISN

\begin{tabular}{|c|c|c|c|c|c|c|}
\hline & \multicolumn{1}{|c|}{ 所不胜 } & 木为土之所不胜 & 火为金之所不胜 & 土为水之所不胜 & 金为木之所不胜 & 水为火之所不胜 \\
\hline IST & $/$ & $/$ & $/$ & & $/$ & / \\
\hline ISN & $\begin{array}{c}\text { elements being } \\
\text { un-restricted }\end{array}$ & $\begin{array}{c}\text { wood being } \\
\text { un-restricted by } \\
\end{array}$ & $\begin{array}{c}\text { fire being } \\
\text { un-restricted by } \\
\text { metal }\end{array}$ & $\begin{array}{c}\text { earth being } \\
\text { un-restricted by } \\
\text { water }\end{array}$ & $\begin{array}{c}\text { metal being } \\
\text { un-restricted by } \\
\text { wood }\end{array}$ & $\begin{array}{c}\text { water being } \\
\text { un-restricted by } \\
\text { fire }\end{array}$ \\
\hline
\end{tabular}

TABLE 8

ThE TRANSLATIONS OF "MU QI”, “ZI QI”, AND "MU Zi XIANG JI” BY IST AND ISN

\begin{tabular}{|c|c|c|c|}
\hline & 母气 & 子气 & (hild qi \\
\hline IST & mother qi & mother and child affecting each other \\
\hline ISN & mother-element qi/mother-phase qi & $\begin{array}{c}\text { child-element qi/child-phase qi/edema of } \\
\text { legs in pregnancy }\end{array}$ & $/$ \\
\hline
\end{tabular}




\section{OVER-RESTRICTION AND COUNTER-RESTRICTION AMONG FIVE XING}

"Xiang Cheng Xiang Wu" are the abnormal situations relative to "Xiang Ke" when the regular restriction among Five Xing becomes disorder and destructive. So "Xiang Ke" and "Xiang Cheng Xiang Wu" usually are categorized as physiological and pathological status respectively.

"Xiang Cheng" is the overwhelming of "restriction", transcending the normal restricting force. Two kinds of situations are included in this abnormal phenomenon (Taking "Earth restrains Water" as example). First, when Water gets week, Earth seizes the opportunity and bullies Water. Under this situation, Earth overwhelms Water. Second, when Earth becomes too strong for other Xing to control, it over-restricts Water.

"Xiang Wu" is the counter-restriction among Five Xing. Also, there are two sorts of situations (Taking "Earth restrains Water" as example). First, when Water is much stronger than its normal state, Earth can not restrain it and it over-restricts Earth. Second, when Earth becomes weaker, Water is relatively stronger than Earth and then it will over-restrict Earth.

ISN translates "Wu Xing Xiang Cheng" and "Wu Xing Xiang Wu" into "over-restriction among five elements/phases" and "counter-restriction among five elements/phases". And IST renders "Xiang Cheng" and "Xiang Wu" into "overwhelming" and "rebellion". "Mu Wu Jin" is translated in "Wood counter-restricting Metal" in ISN and so does other Xing. "Overwhelming" and "over-restriction" imply the information of "restrict too much" while "rebellion" and "counter-restriction" correspond with the original loyally and accurately. Therefore, these translations are workable.

TABLE 9

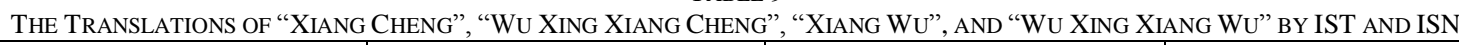

\begin{tabular}{|c|c|c|c|c|}
\hline & (相) 乘 & 五行相乘 & （相）侮 & 五行相侮 \\
\hline IST & overwhelming & / & rebellion & / \\
\hline ISN & 1 & $\begin{array}{c}\text { over-restriction among five } \\
\text { elements/phases }\end{array}$ & 1 & $\begin{array}{c}\text { counter-restriction among five } \\
\text { elements/phases }\end{array}$ \\
\hline
\end{tabular}

TABLE 10

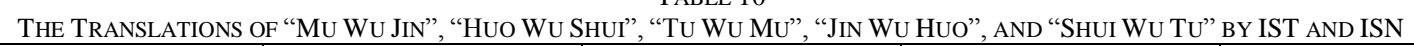

\begin{tabular}{|l|c|c|c|c|c|}
\hline & 木侮金 & 火侮水 & 土侮木 & 金侮火 \\
\hline IST & $/$ & $/$ & $/$ & $/$ \\
\hline ISN & $\begin{array}{c}\text { wood counter-restricting } \\
\text { metal }\end{array}$ & $\begin{array}{c}\text { fire counter-restricting } \\
\text { water }\end{array}$ & $\begin{array}{c}\text { earth counter-restricting } \\
\text { wood }\end{array}$ & $\begin{array}{c}\text { metal counter-restricting } \\
\text { fire }\end{array}$ & $\begin{array}{c}\text { water counter-restricting } \\
\text { earth }\end{array}$ \\
\hline
\end{tabular}

\section{V. "RESTRICTION AND PROMOTION" AND “OVER-RESTRICTION AND RECOVERY”}

The systematic structure of Five Xing contains two kinds of self-adjusted mechanisms - "Zhi Hua" in normal state and "Sheng Fu" under the abnormal situation, to keep itself dynamically balanced and cyclically operative.

Chinese character "Zhi" is "restriction" and "Hua" is "promotion or generation". The adjustment process of "Zhi Hua" means that the systematic structure of Five Xing acquires regulating effects through the interplay between "generation among Five Xing" and "restriction among Five Xing" under a normal condition with the purpose for keeping Five Xing balanced.

From the holistic movement of Five Xing, the relation between any two among Five Xing is bidirectional but not unidirectional one. Any Xing among Five Xing should "generate", "be generated", "restrict" and "be restricted" in order to ensure the right movement of "Zhi Hua". For example, Wood restricts Earth. Earth generates Metal. Metal restricts Wood. Thus, Wood will neither be too full nor fall into a decline, which enables Wood to motivate in a gentle level and then it can work regularly. This principle goes for other Xing.

So, from the above "generating" and "restricting" process, we learn that in the movement of Five Xing, the unbalanced state will be balanced and then the recovered balanced condition will again be broken by new unbalance, which is a circular activity, advancing the continuing changes and development of things.

IST and ISN translate "Zhi Hua" into "inhibition and generation" and "restriction and generation" respectively. Now that Chinese characters "Zhi" and "Hua" are opposite, when translating them into English, we are supposed to use antonym. Therefore, for the translation of "Zhi Hua", neither "inhibition and generation" nor "restriction and generation" is antonym totally. The author proposes that the "generation" be replaced by "promotion" and then "Zhi Hua" be rendered into "restriction and promotion".

"Sheng Fu" adjustment mechanism plays its effect by "generation and restriction" when partial force appears unbalance in Five Xing systematic structure. Through the "Sheng Fu" regulatory mechanism, the unbalanced Five Xing systematic structure becomes balanced again.

Chinese character "Sheng" refers to the over-restriction qi between the adjacent Xing in the process of "restriction among Five Xing". Once "Sheng" qi appears, the opposite force comes to repress it which is called "Fu" qi, the recovery qi. 
For example, we know that Fire restricts Metal. If Fire qi is too much stronger, Fire will over-restrict Metal, causing the debility of Metal qi. Then the weak Metal cannot restrict Wood. Now Wood grows relatively stronger and over-restricts Earth. Earth is restrained and not capable enough to control Water. Eventually, the unscrupulous Water will put down the overwhelming Fire. The Five Xing systematic structure works regularly again. On the contrary, when Fire qi is not enough, it will be over-restricted by Water. Fire becomes weaker, and it cannot restrict Metal so as to make the overfull Metal restricts Wood intensively. Then Wood becomes weaker and unable to restrict Water. Finally, the weakened Water fails to restrict Fire so that Fire qi will get recovered.

Over-restriction and recovery are two parts of the "Sheng Fu" adjustment mechanism, keeping Five Xing systematic structure operate in a balanced way. If any Xing among Five Xing is too full to be restricted by the other Xing, the harmony among Five Xing will be destroyed. So, "Fu", which is the "recovery", plays a significant role in balancing the Five Xing systematic structure.

Since neither IST nor ISN gives the translation of "Sheng Fu", the author would like to offer one version. For the author, it may be most appropriate to translate "Sheng Fu" into "over-restriction and recovery", which conveys the original meanings and basic information of "Sheng Fu".

TABLE 11

THE TRANSLATIONS OF “ZHI HUA” AND "SHENG FU” BY IST AND ISN

\begin{tabular}{|c|c|c|}
\hline & 制化 & 胜复 \\
\hline IST & Inhibition and generation & $/$ \\
\hline ISN & Restriction and generation & $/$ \\
\hline
\end{tabular}

\section{CONCLUSION}

The increasing strong comprehensive national power, the growing national consciousness and the continuing extension of the Belt and Road Initiative lead TCM's going-out an irreversible trend. Comparing WHO International Standard Terminologies on Traditional Medicine in the Western Pacific Region (IST) and International Standard Chinese-English Basic Nomenclature of Chinese Medicine (ISN), the paper analyzes the translations of Five Xing Theory and its core terminologies and eventually it can be concluded that the two standards have advantages and disadvantages in reference to the translation of Five Xing Theory and the given translations about that in these two standards convey the basic connotations loyally in general. However, without equivalent English items, only one or two words would not be able to cover the abundant meanings of some terminologies, like "Wu Xing" and "Xiang Sheng". Therefore, literal translation and transliteration are proposed to be adopted as main strategies, for example, "Wu Xing", "Zhi Hua" and "Sheng Fu" are translated into "Five Xing", "Restriction and Promotion" and "Over-restriction and Recovery". In addition, annotations are needed, for instance, the extended "Mu Zi" from "Xiang Sheng Xiang Ke" should be rendered into "Mother and Child" with its explanation in parentheses, so as to preserve and convey the traditional Chinese culture and help readers understand better.

\section{REFERENCES}

[1] Feiya, Chen. (2000). Analyzation on Translation of TCM's Five Elements. Journal of Shaanxi College of Traditional Chinese Medicine, 4, 62-63.

[2] Guangren, Sun. \& Hongxin, Zheng. (2012). Basic Theories of Traditional Chinese Medicine. Beijing: Chinese Press of Traditional Chinese Medicine.

[3] Jianfeng, Cai. (2014). Longman Dictionary of Contemporary English (the $5^{\text {th }}$ edition). Beijing: Foreign Language Teaching and Research Press.

[4] Ping, Mu. (2009). Shang Shu. Beijing: China Publishing House.

[5] Qiang, Yan. (2016). Brief Analysis on the English Translations of Some Specific Terms of TCM Five-phase Theory. China Journal of Traditional Chinese Medicine and Pharmacy, 31 (07), 2840-2842.

[6] WHO (Western Pacific Region). (2009). Trans. Institute of Integrated Chinese and Western Medicine in the First Hospital of Peking University. WHO International Standard Terminologies on Traditional Medicine in the Western Pacific Region. Beijing: Peking University Medical Press.

[7] Zhaoguo, Li. (2009). Briefly on English Translation of Wuxing. China Terminology, 11 (05), 46-47.

[8] Zhenji, Li. (2008). International Standard Chinese-English Basic Nomenclature of Chinese Medicine. Beijing: People's Medical Publishing House.

Jiaxing Ou was born in Guangdong Province, China. She is currently a postgraduate in the College of Foreign Languages, University of Shanghai for Science and Technology, Shanghai, China. Her major is English Language and Literature.

Yan Hua graduated from University of Shanghai for Science and Technology (USST) in 1996. She is currently associate professor at USST. Her research interests mainly are Australian Literature and Teaching Methodology. 